\title{
DEPOIS DA UNIÃO EUROPEIA: REFLEXÃO SOBRE UMA EXPERIÊNCIA INÉDITA DE DOMINAÇÃO POLÍTICA ${ }^{1}$
}

Philippe Lacour (UnB) ${ }^{2}$

philo@philippelacour.net

Resumo: A União Europeia está morta, mesmo que ela ainda não o saiba. Vários autores expressaram ef etivamente ideias parecidas em relação ao esgotamento desse projeto político original. Crise econômica de 2007, crise migratória, crise política nas instituições, Brexit, crescimento das extremadireitas... Há inúmeros indícios de um enfraquecimento desse edifício supranacional. Enquanto alguns agentes pensam "fundar" novamente o projeto, o ceticismo está crescendo do lado dos povos, particularmente no Sul da Europa. O momento, então, é perfeito para estabelecer um diagnóstico vital sobre essa dinâmica de integração política inédita, entender por que ela não conseguiu atingir seu propósito e, mais radicalmente, o que esse fracasso significa para o futuro da Europa como continente.

Palavras-chave: União Europeia. Dominação política. Crise. Patriotismo. Nacionalismo.

\section{INTRODUÇÃO: ENTRE MAL-ESTAR E MORTE GLÍNICA}

Essa comunicação é um esforço para esclarecer as minhas reflexões políticas, que ainda não estão bem ordenadas. Ele não é, então, um trabalho acadêmico clássico, bem delimitado, sobre um objeto que se exerce domínio, por meio de uma documentação minuciosa, mas apenas uma investigação em curso à medida que aparecem vários indícios que

\footnotetext{
${ }_{1}^{1}$ Recebido em: 15-03-2018/ Aprovado em: 02-12-2018/ Publicado on-line em: 01-02-2019.

2 Philippe Lacour é Professor de Filosofia da Universidade de Brasília, Brasília, DF, Brasil.
} 
vou interpretando como critérios de uma mutação política importante.

É bastante banal dizer hoje que a situação da União Europeia é particularmente crítica. Para muitos observadores, não se trata apenas de um mal-estar, mas sim de uma crise muito forte e de várias dimensões. Gostaria aqui de ir além do diagnóstico da crise, afirmando que a União Europeia está morta, mesmo que ela ainda não o saiba. Esse prognóstico é avançado por vários comentadores políticos, de várias sensibilidades políticas: em jornais gerais, especializados em economia e, às vezes, na forma de publicação para-acadêmica do tipo "blog" - o blog, na verdade, permite tanto o respeito do rigor acadêmico quanto a expressão da opinião pessoal. Deixamos de lado os militantes políticos, que são naturalmente parciais ${ }^{3}$. Do mesmo modo, não estou falando das críticas tradicionais feitas a essa construção institucio$\mathrm{nal}^{4}$, nem dos desafios conceituais que ela implica para a teoria do direito ${ }^{5}$. Não se trata de uma enfermidade, nem de um coma, mas sim de uma morte.

A morte "clínica” da União Europeia é um tema recorrente do livro da jornalista política Coralie Deleaume ${ }^{6}$. É também uma interrogação constante do blog do professor

\footnotetext{
3 Por exemplo, próximo da France Insoumise (ex-Frente de Esquerda): Aurélien Bernier, Désobéissons à l'Union européenne, Paris: Mille et une nuit, 2011.

${ }^{4}$ Cf. LACROIX, Justine. La pensée française à l'épreuve de l'Europe. Paris: Grasset, 2008. Lacroix separa três correntes diferentes, em função do efeito da União Europeia sobre a relação entre direito e política: por um lado, a identidade, por outro, essa identidade pode ser vista como ameaçada (Pierre Manent, Marcel Gauchet et Paul Thibaud), como se transformando numa dimensão cosmopolita (Jean-Marc Ferry, Francis Cheneval, Gérard Mairet), como esperança decepcionada de um novo universalismo pós-identitário (Étienne Balibar, Yves Citton, Étienne Tassin).

${ }_{5}^{5}$ BEAUD, Olivier. Théorie de la Fédération. Paris: PUF, 2007. Disponíveis em: http://bit.ly/2yxvPtu ou http://bit.ly/2gzatoq Acesso em: 12 de novembro de 2017.

${ }^{6}$ DELEAUME, Coralie; CAYLA David. La fin de l'Union Européenne. Paris: Michalon, 2017. Essa jornalista independente escreve também regularmente no seu blog L'arène nue: http://l-arenenue.blogspot.com. Cf Também o seu livro Le couple franco-allemand n'existe pas. Comment l'Europe est devenue allemande et pourquoi ça ne durera pas, Paris, Michalon, 2018.
} 
Jacques Sapir ${ }^{7}$, igualmente do economista alternativo Cédric Durand $^{8}$. É um tema de reflexão do economista da esquerda radical Frédéric Lordon ${ }^{9}$, mas também da jornalista independente Natacha Polony ${ }^{10}$. Todos sublinham um estado de esgotamento do processo de construção dessa "União". O que poderíamos chamar de processo de densificação política acabou, seja na extensão geográfica seja no aprofundamento institucional. O que está acontecendo, ao contrário, é um processo de desagregação que provoca uma reação de pânico por parte dos responsáveis europeus e das elites europeístas ${ }^{11}$, como também novas proposições por parte dos intelectuais animados pelo projeto de uma "outra Europa" que seria, finalmente, democrática e social, como propõe, por exemplo, Thomas Piketty ${ }^{12}$.

Ora, talvez possamos estabelecer uma correspondência entre esse coma e as dificuldades democráticas encontradas ultimamente na expressão da vontade popular. Efetivamente, o "não" Francês e Holandês ao referendum sobre a constituição europeia de 2005 nunca foi totalmente aceito pelas instituições, que preferiram contorná-los pelo Tratado

\footnotetext{
${ }^{7} \mathrm{O}$ blog acadêmico: http://russeurope.hypotheses.fr teve uma frequentação de até 200.000 pessoas por dia, nesses últimos 10 anos.

${ }^{8}$ DURAND, C. (Org.). En Finir avec l'Europe. Paris: La Fabrique, 2013. Esse livro foi bastante lido e discutido, em particular por Jacques Sapir: http://bit.ly/2yyc84R (16 de Maio 2013) e http://bit.ly/2gTFX5E (31 de Maio 2013). Sapir continuou o diálogo com Durand num livro coletivo: SAPIR, J., DURAND, C. et MURER, P. Les scénarii de dissolution de l'Euro, (avec P. Murer et C. Durand) Fondation ResPublica, Paris, septembre 2013.

${ }^{9}$ Frédéric Lordon escreve um blog na plataforma do Monde Diplomatique: http://blog.mondediplo.net/-la-pompe-a-phynance-.

${ }^{10}$ Natacha Polony escreve para vários jornais (inclusive de direita, como Le Figaro); ela anima também um canal alternativo de televisão de jornalismo político: https://polony.tv/.

${ }^{11}$ O responsável pelo Conselho da Europa, Donald Tusk, acabou de lançar uma iniciativa de mais de dez encontros (em dois anos) para dinamizar novamente o projeto europeu...

${ }^{12}$ HENNETTE, S.; PIKETTY T.; SACRISTE, G. et VAUCHEZ, A. Pour un traité de démocratisation de l'Europe. Paris: Seuil, 2017. Veja as resenhas de Wallouzet: http://bit.ly/2hSMe0Z, Shahin Vallée: http://bit.ly/2xUvD7W, e a resposta de Piketty: http://bit.ly/2yWGKgQ.
} 
de Lisboa (2007). Esse "golpe" antidemocrático foi rapidamente esquecido por causa da violência da crise econômica que explodiu durante o ano 2007. As instituições mostraram, durante esses últimos 10 anos, uma incapacidade fundamental de absorver o choque financeiro e de reagir para o bem comum dos vários países membros e de seus povos ${ }^{13}$. De fato, a partir da criação de mecanismos de gestão da crise, sem legitimidade democrática (o famoso Eurogroupe, por exemplo, cuja existência não é prevista por nenhum Tratado), os responsáveis políticos e tecnocráticos impuseram a adoção de políticas de austeridade na Europa do Sul, nas quais o custo humano têm inumeráveis testemunhos, em particular em relação à Grécia - que podemos considerar em situação de crise humanitária equivalente àquela de uma guerra. Todas as instituições, legais ou ilegais, pressionaram os governos não apenas para evitar qualquer política alternativa, mas também qualquer possibilidade de deliberação e de voto democrático direto (tipo referendum): o "não" ao referendum da Irlanda foi contornado (a Irlanda teve que se submeter a um novo voto que, dessa vez, se tornou positivo).

Vários exemplos mostram que os nacionalismos estão de volta, às vezes na pior das formas: xenofobia, discriminação racial ou religiosa, violências diversas, etc. Obviamente, essas manifestações ocorrem em certo contexto de crise: dificuldade econômica na vida cotidiana, desemprego, imigração massiva e às vezes irregular, radicalização terrorista, etc. Mas essas exasperações não devem nos impedir de observar a importância do fenômeno: os povos estão se acordando e reclamam a soberania deles. E as acusações de "populismo" não capturam totalmente a importância do que

\footnotetext{
${ }^{13}$ Conferir as análises precisas e de grande clareza de Romaric Godin no Jornal de economia de centro-direita: La Tribune (http://www.latribune.fr).
} 
está acontecendo, e que é de natureza autenticamente popular. Por outras palavras, se considerar, como dizia De Gaulle, que o patriotismo é o amor a seu pais, enquanto o nacionalismo é o ódio ao pais dos outros, podemos falar de uma volta do patriotismo, embaixo de erupções nacionalistas superficiais - de um neo-nacionalismo. Essa interpretação do que se pode observar na Alemanha (AfD), França (Front National), Hungria, Polônia, Itália, é radicalmente oposta àquela que se pode ouvir na mídia clássica, que precisamente associa patriotismo e nacionalismo, dimensão popular e populista, numa confusão perpétua ${ }^{14}$.

\section{UMA AVALIAÇÃO DA SITUAÇÃO PRESENTE}

Gostaria agora de falar brevemente dos aspectos econômicos, monetários e políticos da situação atual.

(i) Econômicos. Deve-se arriscar um diagnóstico da situação presente na Europa, em particular na Europa do Sul. Os países dessa zona estão sofrendo uma crise econômica enorme, que ainda não acabou, com sérias consequências: pressão muito forte no mundo do trabalho, aumento do desemprego e da terceirização, explosão dos suicídios e dos problemas de saúde mental (depressão, consumo de drogas), dificuldade da acessibilidade à medicina e ao transporte público e às vezes, à educação. Essa crise econômica tem como consequência mais frequente uma explosão da dívida pública. Como as autoridades europeias obrigam a adotar uma política de austeridade, a solução imaginada para sair da crise é sempre a mesma: privatização dos bens públicos (ven-

\footnotetext{
${ }^{14}$ A defesa dos interesses de cada nação é automaticamente e exclusivamente associada à ideologia da supremacia e à xenofobia.
} 
didos para investidores estrangeiros), deflação salarial, redução dos gastos relativos aos serviços públicos (e até destruição deles), precarização dos direitos trabalhistas, etc. Seria inteiramente falso considerar que essa política tenha resultados positivos, apesar do que veicula, de maneira insistente, a mídia tradicional - no caso de Portugal em particular; sem falar do caso da Grécia, no qual as mentiras oficiais são um insulto à inteligência ou um indício de recusa da realidade que está nos limites da esquizofrenia. Deve-se também sublinhar que, apesar de uma situação globalmente melhor, a deterioração da situação acontece igualmente nos países do norte por causa de uma explosão das desigualdades (particularmente na Alemanha, onde o número de trabalhadores pobres chegou a quase $30 \%$ ).

(ii) Monetários. Deve-se, mesmo que seja de maneira breve, falar um pouco da questão do euro. Poucas pessoas sabem que o euro não é uma moeda única mas uma moeda comum. Ora, essa moeda transnacional machuca profundamente todos os seus membros. Isso é particularmente óbvio no caso da Europa do Sul: a supervalorização relativa do euro em relação à produtividade desses países implica necessariamente uma pressão sobre os salários (pois eles não podem desvalorizar), e uma espiral deflacionária. Aparentemente, os países do norte ganham (Alemanha e os satélites monetários dela), mas na verdade eles têm que ser responsáveis por todos os euros que os povos europeus colocam nos bancos alemães, e isso poderia provocar uma catástrofe para eles também. Têm vários comentadores que sublinham que, mesmo que seja discretamente, a Alemanha gostaria de recuperar a sua soberania monetária. Pelo momento, porém, ela aproveita consideravelmente da situação 
(recupera mão de obra altamente qualificada do sul da Europa, faz excedentes comerciais enormes...).

(iiia) Política interna. Paralelamente a degradação da situação econômica e monetária, a escolha governamental (sob "recomendação" da Comissão Europeia) para políticas de austeridade vai sendo aplicada num contexto de controle policial acentuado. Efetivamente, os recentes atentados de ativistas muçulmanos radicais (um cada 6 meses esses últimos três anos) são utilizados, de maneira oportunista e cínica, para justificar a instalação prolongada do "estado de emergência" (mais de 2 anos na França). A extensão indefinida de um regime jurídico extraordinário, normalmente feito para demorar 3 meses ao máximo, aproxima o regime político atual do famoso "estado de exceção". De fato, faz mais de dois anos que a polícia pode agir sem justificação judiciária, impedindo ou reprimindo manifestações, pressionando militantes, vigiando sem limite. Que coincidência: é sob esse controle permanente das forças da ordem que acontece a aplicação das medidas as mais impopulares (destruição dos direitos trabalhistas, moderação salarial, reforma fiscal a favor dos mais ricos). Assim, a raiva popular diante dessas reformas vai se expressando de maneira bem controlada, sem risco de revolução.

Mas se deve também notar que essa evolução se faz, no nível europeu, mediante uma verdadeira ditadura das regras e sob dominação alemã. Já expliquei que os referendum populares de 2005 e 2011 não foram respeitados pelas autoridades europeias. Pode-se também acrescentar que a Alemanha não aplica os famosos critérios de Maastricht (ela respeitas os critérios de gastos públicos, mas não aqueles de excedentes comerciais). Por que, nesse caso, fazer questão de aplicar de maneira tão brutal esses mesmos critérios para os 
países do Sul? Como explicar a presença do Secretariado do Tesouro (norte americano) Timothy Geithner no pior momento da crise, para evitar a Grécia sair do euro? É necessário lançar a hipótese que se trata de um jogo de aliança: o euro (e a união europeia) funcionam no interesse dos Estados Unidos, e a dominação alemã é devida a uma aliança tradicional desse país com Washington, que foi renovado há pouco tempo ${ }^{15}$. A Alemanha é o policial que aplica "a ordem e o progresso" estadunidense no continente europeu, por intermédio da disciplina da Comissão de Bruxelas - ela mesma reivindica de maneira cada vez mais clara a hegemonia na Europa, e até por razoes morais ${ }^{16 !}$ Provavelmente seja por tal razão que a ideia de Cameron de lançar um referendum sobre o Brexit foi fortemente criticada pelo presidente Obama, e que o Brexit inglês deixa o zelador da construção europeia num estado de pânico - eles tentam tudo para cancelar esse voto.

(iiib) Política externa. É preciso sublinhar que a política externa da União Europeia não traz exatamente a paz, ao contrário da propaganda oficial sobre o assunto. O que aconteceu nesses últimos 15 anos foi uma deterioração contínua das relações da União com o exterior, por causa do ativismo da OTAN. Deve-se notar, desse ponto de vista, uma coincidência cada vez mais forte entre a OTAN e a União Europeia, indício de um processo de vassalagem com os Estados Unidos da América. Assistimos à multiplicação das bases da OTAN na Europa do Leste (países bálticos, Polônia), a proliferação das armas estadunidenses posicionadas na Europa, a aparição de situações de crise (em particular

\footnotetext{
${ }^{15}$ A «Aliança germano-americana para o século 21» foi assinada entre Gerhardt Schröder e George Bush o 27 de Fevereiro de 2004. Ela foi confirmada por Angela Merkel o 13 de Janeiro 2006. ${ }^{16}$ MÜNKLER Herfried, "Wir sind der Hegemon. Deutschlands Rolle in Europa”, Frankfurter Allgemeine Zeitung, 21/08/2015, http://bit.ly/2yWZqwX .
} 
na Ucrânia) cujo objetivo é deixar pensar que a Rússia é um perigo que se deve conter - enquanto o avanço das bases da OTAN só pode ser considerado uma agressão da parte da Rússia (como também da China).

Desse ponto de vista, pode-se observar uma mudança radical na política externa da França desde 2007. Todo mundo se lembra do "não" Francês no conselho de segurança da $\mathrm{ONU}$, em 2003, à guerra ilegal contra o Iraque. Já, um pouco depois, em 2005, o presidente Jacques Chirac aceitou mandar soldados ao Afeganistão para ajudar os Estados Unidos na guerra contra "o terror". Mas é com Sarkozy, em 2007, que tudo muda: reintegração da França no núcleo de direção da OTAN (integrada por imposição), participação na guerra na Líbia, no Mali, no Iraque e na Síria, alinhamento radical da posição francesa com Washington em relação ao Oriente Médio... É possível interpretar essa mudança radical da maneira seguinte: em 2003, decepcionada pela reação dos seus aliados diante da decisão estadunidense unilateral de atacar o Iraque, Condoleeza Rice decidiu "perdoar a Rússia, ignorar a Alemanha e punir a França", como se esse país fosse uma criança mimada exasperando todo mundo. Além disso, a importância da França está ligada ao fato de deter um posto permanente no Conselho de Segurança da ONU. Daí, talvez, certo número de pressão que explicam a situação atual de vassalizaçao. Adicionaria que a lógica dessa mutação é de continuar da maneira seguinte: expulsar a França desse Conselho Permanente, insistindo sobre uma comunitarização desse posto permanente para um representante da União europeia (que será dirigido, discretamente ou não, por um Alemão). A Alemanha está indo nessa direção, também tentando uti- 
lizar a União Europeia para ter acesso à força nuclear francesa. Se ela conseguir esse intento, a operação de castração da França pelos seus “aliados ocidentais” terá atingido seu objetivo.

Devemos adicionar um último ponto, que parece ser de política interior, mas é na verdade um tema de política externa. No momento atual, o risco de desintegração das identidades nacionais é real. O exemplo do voto na Catalunha mostra que, sob a forma de um processo aparentemente democrático (o direito dos povos de decidir por eles mesmos), trata-se de um processamento de fragmentação de um Estado-nação com uma velha tradição, e que é potencialmente perigoso (porque a guerra civil na Espanha é relativamente recente e as forças armadas são muito dedicadas à preservação da integridade territorial da nação). Ora, esse processamento foi apenas timidamente criticado pela Comissão, que se pronunciou antes a favor de uma autonomia maior de todas as euro-regiões, em particular a Catalunha, a Escócia, a Lombardia, etc. Pode-se perfeitamente interpretar essa sequência, de um ponto de vista geopolítico, como um esforço para dividir, enfraquecer, e assim, dominar melhor.

\section{VIVE LA FRANCE?}

Quando falar "Vive la France", seria apenas da minha parte uma retomada de um nacionalismo arrogante, isto é, uma forma de regressão moral, psicológica e histórica? Gostaria de explicar que não. Não se trata aqui de retomar apenas a ideia de De Gaulle, segundo o qual o patriotismo é o amor ao seu país, enquanto o nacionalismo é o ódio ao país dos outros - "nós não somos nacionalistas, dizia ele, nós somos 'nacionais"'. Trata-se, mais profundamente, da liberdade, 
ou melhor, de uma libertação, isto é, de uma reconquista da democracia. Trata-se de sair de uma era curiosamente pósdemocrática.

Mas, voltamos um momento para o maior risco implicado pela sequência atual: a desintegração dos estados-nações da Europa enquanto formas de organização da vida política que têm uma grande tradição histórica. Esse risco é real, como mostra a situação atual na Catalunha. Não aceito totalmente a ideia de que a reivindicação dos independentistas seja "democrática”, baseada sobre o direito fundamental dos povos de decidir por si mesmos - qualquer que seja a responsabilidade do governo de Madrid. Pois a demanda tem como objetivo uma independência "dentro da UE", cujo estatuto democrático é particularmente duvidoso, como expliquei. Se essa leitura de auto-emancipação não é totalmente coerente, passemos um momento para um olhar geopolítico, pois, é freqüentemente a geopolítica que comanda a política, no sentido que a política interna apenas reage as intenções agressivas (pressões, ingerência) de inimigos exteriores. O resultado é aquele de uma fragmentação da Espanha, do velho Estado espanhol, da destruição da Espanha como nação plural: existe doravante uma articulação de um Estado-região com um conjunto federal (a UE). Isso quer dizer que as decisões da Comissão Europeia são validadas diretamente pelo governo da Catalunha - o nível nacional espanhol, então, não existe mais na tomada de decisões. Foi assassinado o Estado espanhol. Ora, a dica do detetive consiste em se perguntar “Quem aproveita do crime?”. Por exemplo, no caso de uma decisão de criação de um imenso mercado de livre troca entre América do Norte e Europa, ou a Europa e a China, não existe mais reações negativas da parte dos Estados, recriminações, críticas, pedidos para mais 
transparência... Dividir para reinar/dominar: isso é um velho princípio da compreensão das relações internacionais e não vejo por que não se poderia utilizar aqui. Quem sai fortalecido, então, são os grandes interesses não-democráticos do capitalismo financeiro transnacional e, claramente, não a democracia.

Nesses últimos anos, têm surgido várias discussões entre intelectuais para saber como priorizar uma saída dessa situação seja ela de esquerda ou de direita ${ }^{17}$. De fato, há intelectuais (economistas-filósofos) que se posicionaram na esquerda radical (Lordon) e na direita radical (Sapir). Na minha opinião, trata-se de um falso debate. Em primeiro lugar, porque nem a Frente de Esquerda nem a Frente Nacional (nem Debout la Republique, partido que acompanha Sapir) propõem, de maneira absolutamente clara, uma saída da UE (e do Euro): a última campanha eleitoral francesa mostrou a ambiguidade desses partidos em relação a essa proposição simples. A solução seria então juntar os vários partidos políticos numa frente comum? Essa era precisamente a verdadeira ideia de Jacques Sapir (e não uma saída de direita, como acusou F. Lordon), baseada sobre a observação justa de uma maioridade de votos a favor de partidos "soberanistas" na última eleição presidencial"18 - aqui "soberanismo" é utilizado no sentido largo para designar todos os partidos euro-céticos ${ }^{19}$. Efetivamente, essa lógica da "frente comum" faria sentido para se opor ao que o próprio Lordon

\footnotetext{
${ }^{17}$ Cf. Frédéric Lordon, «Clarté», 26 août 2015, http://blog.mondediplo.net/2015-08-26-Clarte, conclusão.

${ }^{18}$ Jacques Sapir, « Réflexions sur la Grèce et l'Europe », 21 août 2015, http://russeurope.hypotheses.org/4225 (parte: « Comment reconstruire une alternative à la politique européenne actuelle? »); et «A nouveau sur les 'Fronts' », 27 août 2015, http://russeurope.hypotheses.org/4244.

${ }^{19}$ Isto é, céticos e críticos em relação à construção europeia atual (UE).
} 
condena com uma ironia sarcástica: o falso internacionalismo dos cretinos "alter-europeistas" e "alter-globalistas" (uma outra Europa é possível, como também uma outra globalização) ${ }^{20}$. Os profetas e zeladores de uma "outra Europa possível" são os "idiotas úteis" da globalização brutal, que a construção europeia atual apenas intensifica.

Para lutar contra essa onda, tem que sair mesmo dela. E por isso, e apenas por isso, que temos que valorizar hoje em dia um novo "nacionalismo": porque ele é o lugar tradicional de uma soberania popular efetiva, e a base de um verdadeiro inter-nacionalismo, isto é: a criação de laços entre várias nações, que é o contrário da fusão de várias nações dentro de um conjunto "europeu", "ocidental" ou "global". Não é por acaso, então, que os militantes desse "novo nacionalismo" insistem também sobre uma saída da aliança do Atlântico Norte, cujo ativismo militarista na Europa do Leste é particularmente preocupante. Contra as guerras neocoloniais da OTAN na Líbia, por exemplo, os neo-nacionalistas sublinham que a base das relações internacionais (desde a secunda guerra mundial) é o direito internacional, com os seus princípios fundamentais (a soberania dos Estados implica um dever de respeito da integridade territorial e de não-intervenção nas decisões internas do governo). $\mathrm{O}$ neo-nacionalismo, então, é uma escolha coerente a favor de uma saída finalmente efetiva, eficiente da globalização e do neo-liberalismo que vão destruindo, de maneira implacável, todos os direitos sociais adquiridos ao longo do século 19 e 20 na Europa. O neo-nacionalismo, então é também a promessa de uma outra política internacional, com novas associações: em particular, não vejo por que a França seria

\footnotetext{
${ }^{20} \mathrm{~F}$. Lordon, «Leçons de Grèce à l'usage d'un internationalisme imaginaire (et en vue d'un internationalisme réel)».
} 
forçada a se considerar enquanto parte do "campo ocidental” e não fazer aliança com países dos Brics.

\section{GonGlusão: UMA NOVA FORMA DE OBSTÁGULO À VERDADE}

Eu disse antes que se trata de sair de uma época curiosamente pós-democrática. Sublinhei o advérbio "curiosamente", porque essa forma de dominação é surpreendente: é difícil de identificar e definir. Para precisar essa situação, gostaria de utilizar aqui a noção de "recouvrement" de Alain Badiou. Este relaciona essa figura à ideologia contemporânea da finitude (repressão de todo pensamento que seria potencialmente infinito; imposição da finitude por fidelidade identitária; atomização, individualização; esterilização da língua; e finalmente o recouvrement: o fato de cobrir uma abertura potencialmente infinita - Badiou a considera um procedimento maior e mais mecânico de imposição da finitude). Quando surge algo novo, criador, potencialmente infinito, tenta-se anulá-lo, fingindo que essa novidade seja apenas uma figura da velha ordem das coisas. Ao utilizar essa interpretação "clássica”, se nega a novidade revolucionaria dessa aparição. Uma forma desse recouvrement é a "recuperação" econômica ou política de um movimento social. O resultado é a desvalorização do que aconteceu, porque o valor imanente da verdade nova é "coberta" por algo alheio, de valor tradicional, por assimilação da sua identidade a uma identidade superior, por atomização da ideia carregada (cujas consequências são infinitas), por falsificação da linguagem para falar dela.

Estamos então hoje em dia tipicamente num momento de "encobrimento" da democracia na Europa, não apenas 
por causa do capitalismo, mas também por razões classicamente geopolíticas de desejo de dominação. A novidade dessa sequência "imperialista” é que ela não se apresenta como tal (como podia ser o caso no século 20), mas que ela se esconde, atrás de uma maquiagem midiática particularmente forte, repetitiva, sedutora, convincente. Vários observadores notaram ultimamente uma degradação impressionante do nível de senso crítico da mídia europeia, na França e também na Alemanha.

Então, talvez você esteja pensando que eu estaria exagerando... Porém, nesse caso, como pode-se explicar que todas as análises que mencionei foram feitas por jornalistas que tiveram que enfrentar ultimamente uma violência institucional muito forte, na forma da censura (Sapir 21), do desemprego (Godin ${ }^{22}$, Lancelin ${ }^{23}$, Polony ${ }^{24}$ ), da marginalização (Deleaume ${ }^{25}$ ), enquanto, ao mesmo tempo, o Front National sempre teve acesso à grande mídia, como para associar melhor a crítica da União Europeia, do Euro e da OTAN ao racismo, à xenofobia e a uma visão reacionária da vida em comum? O "recouvrement” está sendo aplicado. Eu duvido, porém, que possa convencer todo mundo do que

\footnotetext{
${ }^{21}$ Em setembro 2017, Jacques Sapir foi proibido de escrever o seu blog na plataforma hypotheses.org pelo diretor da Open Edition, Marin Dacos, sem razão relevante: https://www.les-crises.fr/invite-russeurope-en-exil-force-par-jacques-sapir/. Ora, Marin Dacos tinha sido nomeado conselho especial do governo Macron para as novas tecnologias pouco antes.

${ }^{22}$ Quando o Jornal La Tribune decidiu de fechar o seu serviço de Macroeconomia, Romaric Godin, que era Rédacteur en chef adjoint, foi demitido (o 9 de Fevereiro de 2017).

${ }^{23}$ Aude Lancelin foi demitida do Jornal Le Nouvel Observateur, o 10 de Maio 2016, como relata Henri Maler: http://www.acrimed.org/Aude-Lancelin-viree-de-L-Obs-un-chef-d-oeuvre-de. Ela mesma respondeu a essa brutalidade com um livro de denúncia: La pensée en otage. S'armer intellectuellement contre les médias dominants, Paris, Les liens qui libèrent, 2018/

${ }^{24}$ Natacha Polony foi demitida de uma rádio (Europe 1) e de uma televisão (Paris Pemière) em Junho 2017: http://www.leparisien.fr/laparisienne/actualites/people/natacha-polony-evincee-d-europe1-apres-paris-premiere-16-06-2017-7056690.php

${ }^{25}$ Coralie Deleaume escreve um blog e tem dificuldade para ter acesso a grande mídia. Ela trabalha apenas para jornais digitais.
} 
popular quer dizer apenas populista, e patriota apenas nacionalista.

Abstract: The European Union is dead, even if it does not know it yet. Indeed, several authors have expressed similar ideas regarding the exhaustion of this original political project. The 2007 economic crisis, the current migratory crisis, the institutional political crisis, the Brexit vote, the growth of the extreme right... There are countless signs of a weakening of this supranational project. While some wish to "found" the project again, skepticism is growing on the side of the people, particularly in Southern Europe. The time has come to establish a vital diagnosis of this unprecedented dynamic of political integration, to understand why it has failed to achieve its purpose and, more radically, what this failure means for the future of Europe as a continent.

Keywords: EU. Brexit. Democracy. Failure. Nation. Truth. France.

\section{REFERÊNGIAS}

BALIBAR, Etienne. Nous, citoyens d'Europe? Les frontières, l'État, le peuple, La Découverte, 2001.

. L'Europe, l'Amérique, la Guerre. Réflexions sur la médiation européenne, La Découverte, 2003.

. Europe, Constitution, Frontière, éditions du Passant Passant, 2005.

. Europe, Crise et fin? Éditions Le Bord de l'eau, collection «Diagnostics», 2016.

BEAUD Olivier, Théorie de la Fédération, Paris, PUF, 2007; veja essas resenhas, por exemplo: http://bit.ly/2yxvPtu ou: http://bit.ly/2gzatoq.

BERNIER Aurélien, Désobéissons à l'Union européenne, Paris, Mille et une nuit, 2011. . La gauche radicale et ses tabous, Pourquoi le Front 
de gauche échoue face au Front national, Paris, Seuil, 2014.

CHENEVAL, Francis; Professor de Filosofia Política, Universidade de Zürich, http://bit.ly/2yRf6ks.

. "L'euro et l'Europe cosmopolitique: des logiques contraires?", in Auffray-Seguette, Marie; Ferry, Jean-Marc; Leclerc, Arnauld. Europe: Crise et critique. Paris: Pups Presse de l'université de Paris-Sorbonne, 191-220.

. with Lavenex, Sandra; Schimmelfennig, Frank (2015). "Demoi-cracy in the European Union: Principles, Institutions, Policies", Journal of European Public Policy, 22(1):1-18.

. "Towards a More Legitimate Form of Direct Democracy in the European Union", Bruxelles/Utrecht: European Commission, 2016.

. with Nicolaidis, Kalypso (2017), "The social construction of demoicracy in the European Union", European Journal of Political Theory, 16(2):235-260.

DELEAUME Coralie (et CAYLA David), La fin de l'Union Européenne, Paris, Michalon, 2017.

. Le couple franco-allemand n'existe pas-Comment l'Europe est devenue allemande et pourquoi ça ne durera pas, Paris, Michalon, 2018.

. blog L'arène nue: http://l-arene-nue.blogspot.com.

DURAND Cédric (dir.), En Finir avec l'Europe, Paris, La Fabrique, mai 2013. Esse livro foi bastante lido e discutido, em particular por Jacques Sapir: http://bit.ly/2yyc84R (16 
de Maio 2013) e http://bit.ly/2gTFX5E (31 de Maio 2013). . com Sapir J. e Murer P., Les scénarii de dissolution de l'Euro, Fondation ResPublica, Paris, septembre 2013.

FERRY Jean-Marc, Discussion sur l'Europe, Paris, 1992 Calmann-Lévy, (en collaboration avec Paul Thibaud).

. La Question de l'État Européen, Paris, 2000, Éditions Gallimard, Collection "NRF-essais".

. L'Europe, l'Amérique et le monde, Nantes, 2004, Éditions Pleins Feux.

. Europe, la voie kantienne. Essai sur l'identité postnationale, Paris, 2005, Éditions du Cerf, Collection "Humanités".

. L'École au défi de l'Europe. Médias, éducation et citoyenneté postnationale, Bruxelles, Éditions de l'Université de Bruxelles, 2006.

. La république crépusculaire. Comprendre le projet européen in sensu cosmopolitico Paris, Cerf, coll. "Humanités", 2010.

. L'Europe interdite, Paris, Éditions de Passy, 2012.

. L'Idée d'Europe, Paris, Presses de l'Université ParisSorbonne, 2013.

GAUCHET Marcel, codiretor (rédacteur en chef) da Revista generalista Le Débat, http://le-debat.gallimard.fr/.

. "Le Problème européen", Le Débat, n ${ }^{\circ}$ 129, marsavril 2004. 
. "Comment l'Europe divise la France. Un échange", (avec René Rémond), Le Débat, $\mathrm{n}^{\circ}$ 136, septembre-octobre 2005.

GODIN Romaric, lista de artigos no Jornal La Tribune, http://bit.ly/2yJRVX7.

LACROIX Justine, La pensée française à l'épreuve de l'Europe, Paris, Grasset, 2008.

LORDON Frédéric, Économistes à gages (avec Serge Halimi et Renaud Lambert), coll. "Prendre parti", Paris, Les liens qui libèrent \& Le Monde diplomatique, 2012.

. La Malfaçon: monnaie européenne et souveraineté démocratique, Paris, Les liens qui libèrent, 2014.

. On achève bien les Grecs: chroniques de l'Euro 2015, Paris, Les liens qui libèrent, 2015.

- blog na plataforma do Monde Diplomatique: http://blog.mondediplo.net/-la-pompe-a-phynance-.

"Clarté", 26 août 2015, http://blog.mondediplo.net/201508-26-Clarte.

"Leçons de Grèce à l'usage d'un internationalisme imaginaire (et en vue d'un internationalisme réel)", http://bit.ly/1DYQmCZ.

MAIRET Gérard, Discours d'Europe. Souveraineté, citoyenneté, démocratie, La Découverte, 1989.

. La Fable du monde. Enquête philosophique sur la liberté de notre temps Gallimard, 2005. 
MANENT Pierre, membro do Comitê de Redação da Revista Commentaire, https://www.commentaire.fr/.

. La Raison des nations: Réflexions sur la démocratie en Europe. Gallimard, collection "l'esprit de la cité", 2006.

. "Repurposing Europe", Revista Fist Things, Abril 2016, http://bit.ly/2eSSSDL (extrato do livro a ser publicado: Beyond Radical Secularism: How France and the Christian West Should Respond to the Islamic Challenge).

MÜNKLER Herfried, "Wir sind der Hegemon. Deutschlands Rolle in Europa", Frankfurter Allgemeine Zeitung, 21/08/2015, http://bit.ly/2yWZqwX.

PIKETTY Thomas, S. Hennette, G. Sacriste et A. Vauchez, Pour un traité de démocratisation de l'Europe, Seuil, 2017. Veja as resenhas de Laurent Wallouzet: http://bit.ly/2hSMe0Z, Shahin Vallée: http://bit.ly/2xUvD7W, e a resposta de Thomas Piketty (et alii): http://bit.ly/2yWGKgQ.

POLONY Natacha, coluna no jornal Le Fígaro: http://plus.lefigaro.fr/page/natacha-polony.

. canal alternativo de televisão de jornalismo político: https://polony.tv/.

. Changer la vie. Pour une reconquête démocratique, Paris, Editions de l'Observatoire, 2017.

SAPIR Jacques, escreve no blog acadêmico: http://russeurope.hypotheses.fr, que teve uma frequentação de até 200.000 pessoas por dia, nesses últimos 10 anos. O blog foi censurado em Setembro 2017. 
. La Fin de l'eurolibéralisme, Le Seuil, 2006.

. Le nouveau XXI siècle, du siècle américain au retour des nations, Le Seuil, 2008.

. La Démondialisation, Paris, Le Seuil, 2011.

. Faut-il sortir de l'euro?, Paris, Le Seuil, 2012.

. Souveraineté, démocratie, laïcité, éditions Michalon, 2016, 326 pages.

. L'euro contre la France, l'euro contre l'Europe, Le poing sur la table, éditions du Cerf, 2016.

TASSIN Etienne, "Europe: a political community?", Dimensions of Radical Democracy: Pluralism, Citizenship and Community, edited by Chantal Mouffe, Verso, London, 1992, p.169-192.

. "L'Europe entre philosophie et politique", L'Identité philosophique européenne (J. Poulain et P. Vermeren, dir.), Paris, L'Harmattan, 1993, p. 189-210.

. "Identités nationales et citoyenneté européenne", Esprit, Paris, 1/janvier 1994, p. 97-111.

. "La identidad europea", Leviatàn, 56, Madrid, Verano 1994, p. 25-39.

. "De l'Europe philosophique à l'Europe politique", Existe-t-il une Europe Philosophique?, sous la direction de N. Weil, Ed. de l'Aube, 2005.

- "L'Europe cosmopolitique et la citoyenneté du monde", Raison Publique, 10 mars 2010, http://www.raison-publique.fr/article229.html. 
THIBAUD Pierre, ex-diretor da Revista Esprit; ainda faz parte do Comitê de Redação.

. "Europe ratée, Europe à faire", Le Débat, n¹36, 2005/4, http://bit.ly/2zDkvJh.

. “Quel cap pour l'Europe?", Le Monde Diplomatique, janv 2007, http://bit.ly/2yMFHi3.

. avec Edgard Morin, "Que reste-t-il de l'universel européen?", Libération, 27 nov. 2009, http://bit.ly/2zOVMCk. 